\title{
CARÁTER E TRABALHO NO NOVO CAPITALISMO
}

por Tânia Cristina Alves de Siqueira*

SENNETT, Richard. A corrosão do caráter: as conseqüências pessoais do trabalho no novo capitalismo. Rio de Janeiro: Record, 1999. 204p.

Sennett, professor de Sociologia da Universidade de Nova York e da London School of Economics, tornou-se reconhecido nos meios acadêmicos brasileiros por seu livro $O$ declínio do homem público. Em seu estudo, objeto desta resenha, que tem por título A corrosão do caráter: as conseqüências pessoais do trabalho no novo capitalismo, a intenção do autor não é relatar os danos psicológicos resultantes do novo capitalismo flexível, mas visa à compreensão das grandes mudanças que vêm ocorrendo no mundo do trabalho, de um modo específico, e na sociedade, de um modo geral.

Essas mudanças, por sua vez, decorrem do novo capitalismo que, ao enfatizar a flexibilidade, origina novas estruturas de poder e de controle. Essa nova circunstância, que tem como característica o curto prazo, "corrói o caráter", isto é, não possibilita o desenvolvimento de experiências que favoreçam a sua formação e, semelhante a um gesto intimidativo, obstaculiza as qualidades e as capacidades que as pessoas têm para transformarem seus caracteres em narrativas sustentadas, especialmente "aquelas qualidades de caráter que ligam os seres humanos uns aos outros, e dão a cada um deles um senso de identidade sustentável" (p. 32).

O novo capitalismo parece rechaçar tudo aquilo que é estável ou que pressupõe estruturas rígidas. Desse modo, há críticas à rotina

Tânia Cristina Alves de Siqueira é aluna do Doutorado do Departamento de Sociologia da Universidade de Brasília. 
e aos horários rígidos, as organizações altamente burocráticas são preteridas em favor de organizações mais planas e flexíveis, as organizações hierárquicas, tipo pirâmide, são substituídas por organizações em redes.

Mediante a contestação da estabilidade no posto de trabalho, que foi conseguida após a Segunda Guerra Mundial, a proposta que se consolida é a do trabalho a curto prazo, por contrato ou episódico, e, assim, exige-se cada vez mais do "novo" trabalhador projetos a curto prazo, estar constantemente aberto as mudanças e o desafio de correr riscos que podem perfeitamente ser compreendidos como um modo de viver na ambigüidade e na incerteza. Tudo parece indicar que a possibilidade de construção de uma carreira e o aproveitamento de um conjunto de qualificações ao longo de uma vida de trabalho chegou a seu termo.

Diferentemente da antiga hierarquia de trabalho valoriza-se, atualmente, o trabalho em equipe, o qual imprime uma ilusão de que trabalhadores e chefes não são antagonistas. Esta negação, por sua vez, legitima a posição dos que estão por cima e, desse modo, o poder apresenta-se, tal como afirma Sennett, "nas cenas superficiais de trabalho de equipe, mas sua autoridade está ausente" (p. 136), o que permite àqueles que estão no controle imprimirem mudanças, adaptações, reorganizações, "sem ter que justificar-se ou a seus atos" (p. 137).

Desse modo, entrelaça-se a essa maneira de viver, possibilitada pela nova economia, a sensação de deriva no tempo, de lugar em lugar, de emprego em emprego, de incerteza, da perda de confiança em si e nos outros e de permanência num estado contínuo de vulnerabilidade.

A partir desse horizonte, Sennett, ao longo dos oito capítulos que compõem o livro, analisa o que vem ocorrendo no âmbito dos valores, das relações interpessoais, dos afetos, enfim, de mudanças que repercutem em diferentes setores da vida social e que não se limitam ao mundo do trabalho. Trata-se de uma análise que busca evidenciar, na individualidade, na particularidade dos trabalhadores, 
as conseqüências, nem sempre aparentes, que resultam desse novo modo de produção flexível.

Demonstra a sua proposição mediante o esclarecimento de questões que estão sendo impostas ao caráter pelo novo capitalismo flexível, quais sejam: "Como decidimos o que tem valor duradouro em nós numa sociedade impaciente, que se concentra no momento imediato? Como se podem buscar metas a longo prazo numa economia dedicada ao curto prazo? Como se podem manter lealdades e compromissos mútuos em instituições que vivem se desfazendo ou sendo continuamente reprojetadas?" (p. 11-12).

Sennett, com grande habilidade, vai perseguir as suas questões e desenvolver sua refinada argumentação mediante uma cuidadosa narração. Esta foi construída não apenas por intermédio ou referência a uma vasta bibliografia que, assevera-se foi utilizada de um modo preciso e meticuloso, onde se perfilam autores como Diderot, Max Weber, Foucault, Antony Giddens, Gadamer entre outros.

Utiliza-se também, para construir essa narrativa, de entrevistas, histórias de vida, observação cuidadosa com: pai e filho representando duas gerações, uma pertencendo a um mundo altamente burocratizado e de longo prazo, e outra pertencendo a um mundo caracterizado pela flexibilidade e fluxo a curto prazo respectivamente, em que o fosso que separa essas duas gerações está na maneira de organizar o tempo, sobretudo o tempo de trabalho; funcionários e ex-funcionários de grandes empresas que optaram pela reengenharia ou modelos flexíveis; padeiros de Boston; a dona de um bar em nova York que arriscou mudar de ramo; os homens poderosos de Davos - que, de acordo com o autor, é o reino dos conquistadores - chefes de grandes bancos ou líderes empresarias e políticos - e devem muito de suas conquistas à prática da flexibilidade. E o que há de comum em todos eles são as marcas deixadas pelo novo capitalismo.

O sistema de trabalho dentro desta nova lógica dá primazia ao curto prazo que, por sua vez, desvaloriza o trabalho como instância formadora de valores. Para Sennett:

o termo caráter concentra-se sobretudo no aspecto a longo prazo de nossa experiência emocional. É expresso pela lealdade e compromisso 
mútuo, pela busca de metas a longo prazo, ou pela prática de adiar a satisfação em troca de um fim futuro. Da confusão de sentimentos em que todos estamos em algum momento em particular, procuramos salvar e manter alguns; esses sentimentos sustentáveis servirão a nossos caracteres. Caráter são os traços pessoais a que damos valor em nós mesmos, e pelos quais buscamos que os outros nos valorizem. (p. 10-11).

Nessa nova lógica, caracterizada pela flexibilidade, o trabalhador deve estar aberto às mudanças e ao risco. Esses elementos, por sua vez, acarretam no indivíduo sentimentos de insegurança e medo, relativos ao controle de sua vida. Para o autor, há uma perda do senso de comunidade e a tentativa de transformar em seu correlato as comunicações eletrônicas, que se caracterizam por sua brevidade, pressa e inconsistência.

Sennett chama a atenção para o fato de que no capitalismo "não flexível", após a Segunda Guerra Mundial, havia a possibilidade de organizar o futuro, na medida em que houve gerações que puderam desfrutar de uma relativa segurança, viabilizada pela ação sindical e pelo sistema previdenciário amplo. O trabalho era para sempre e tinha como objetivo servir à família. Operava-se no longo prazo, o tempo era linear com conquistas cumulativas e segurança no emprego. Construía-se uma narrativa de vida a partir dos ganhos obtidos com o trabalho. Havia a possibilidade de mobilidade ascendente para os filhos.

Não operar no longo prazo poderia ser, para Sennett, o lema do trabalhador moderno. Exige-se do trabalhador flexibilidade e disposição para assumir riscos contínuos. Houve uma ruptura com a idéia de ir alcançando gradativamente postos fixos na hierarquia de uma empresa. No novo capitalismo o tempo de curto prazo, flexível, "parece excluir que façamos uma narrativa constante de nossos labores, e portanto uma carreira" (p. 146).

Há uma dimensão que não é anunciada quando se busca enfatizar as características distintivas do capitalismo de nossa época. O "não há longo prazo" desorienta os indivíduos e suas famílias. Segundo Sennett, o que mais afeta a vida emocional das pessoas fora 
do local do trabalho é "a dimensão do tempo no novo capitalismo, e não a transmissão de dados high-tech, os mercados de ações globais ou o livre comércio" (p. 25). Redimensionado para o âmbito familiar, "não há longo prazo" significa mudar, não se comprometer, não se sacrificar.

As mudanças no mundo do trabalho requeridas pelo capitalismo flexível e o sentido de risco que pode ser expresso como mudanças laterais ambíguas, perdas retrospectivas e resultados salariais imprevisíveis tornam muitas vezes ilegível o processo relativo à mobilidade ocupacional nas sociedades contemporâneas. E, em face desses acontecimentos, Sennett destaca o medo das classes em relação a esse processo. Como o fracasso tornou-se o grande tabu moderno, ele atinge não apenas os pobres ou desprivilegiados, mas "tornou-se mais conhecido como um fator regular nas vidas da classe média" ( $p$. 140). Este sentimento de medo e a possibilidade do fracasso, por sua vez, alcançam o âmbito familiar, pois as qualidades do bom trabalho não são as mesmas do bom caráter, pois há dificuldades em "oferecer aos filhos a substância de sua vida de trabalho como exemplo de como conduzir-se eticamente" (p. 21).

Na avaliação de Sennett, a lógica do curto prazo, a necessidade de adaptar-se constantemente está solapando valores como lealdade e confiança. As mudanças que vêm ocorrendo nas empresas e, de um modo geral, consideradas acertadas ou sensatas, são, no entanto, enganosas.

Sennett busca relatar a passagem de um tipo de capitalismo de classe para um tipo de capitalismo flexível. Este novo capitalismo vem permitindo uma economia mais dinâmica, em que valores como compromisso e integridade estão sendo substituídos por outros, que permitem apenas laços muitos superficiais entre os trabalhadores o que, por sua vez, não possibilita uma reação organizada. Este modelo de trabalho flexível do novo capitalismo que visa à superação da rotina, do tempo burocrático, tem um sistema de poder que se "esconde nas modernas formas de flexibilidade" e é constituído por três elementos: "a reinvenção descontínua das instituições, especialização flexível de produção, concentração de poder sem centralização" (p. 54). 
Parece que os que estão mais adaptados a este novo processo encontravam-se em Davos (Fórum Econômico Mundial). Estes são os poucos vencedores, que têm a capacidade de desprender-se do passado e aceitar a flexibilização e que não se preocupam com os muitos perdedores que o processo vai deixando no meio do caminho. Assinala também que esta capacidade de desprender-se do passado e a confiança para aceitar a flexibilização são características que podem se tornar autodestrutivas para aqueles que trabalham mais embaixo na hierarquia. Desse modo, "os três elementos do sistema de poder flexível corroem o caráter de empregados comuns, que tentam jogar segundo essas regras" (p. 73).

Por fim, gostaríamos de ressaltar que é uma grande contibuição para decifrarmos o que hoje é denominado pela literatura especializada de capitalismo flexível. Poderíamos, apressadamente, classificar esse relato como pessimista, por exemplo no que diz respeito à construção de uma narrativa de vida coerente diante das mudanças rápidas e da constante fragmentação. No entanto, negaremos tal sentença. Primeiramente, elogiando o aspecto não nostálgico de seu estudo. Sennett identifica e ressalta o dinamismo da nova economia. No entanto, seu esforço consiste em apontar questões que desestabilizam os indivíduos tanto no âmbito pessoal quanto no profissional. Esta situação de instabilidade que hoje se coloca, praticamente mina a possibilidade para se organizar o futuro. Mesmo diante desse quadro o autor assevera que "um regime que não oferece aos seres humanos motivos para se ligarem uns aos outros não pode preservar sua legitimidade por muito tempo". Desse modo parece sinalizar à comunidade como aquilo que se não combate, ao menos alivia e pode auxiliar-nos a enfrentar o novo capitalismo mediante aqueles traços pessoais a que damos valor em nós mesmos, e pelos quais buscamos que os outros nos valorizem. Segundo Sennett, esses traços "se expressam pela lealdade e compromisso mútuo, pela busca de metas a longo prazo, ou pela prática de adiar a satisfação em troca de um fim futuro". 